\title{
A critical evaluation of the application of biomarkers in epidemiological studies on diet and health
}

\author{
C. P. Wild ${ }^{1 *}$, C. Andersson ${ }^{2}$, N. M. O’Brien ${ }^{3}$, L. Wilson $^{4}$ and J. A. Woods ${ }^{3}$ \\ ${ }^{1}$ Molecular Epidemiology Unit, Academic Unit of Epidemiology and Health Services Research School of Medicine, \\ University of Leeds, $U K$ \\ ${ }^{2}$ National Food Administration, Box 622, S-751 26 Uppsala, Sweden \\ ${ }^{3}$ Department of Food Science and Technology, University College, Cork, Ireland \\ ${ }^{4}$ Central Science Laboratory, Sand Hutton, York, UK
}

\section{Contents}

1. Introduction (C. Wild) S38

2. Sample collection, processing and storage (L. Wilson) S38

2.1. Collection S39

2.2. Transportation $\quad$ S39

2.3. Storage S39

2.4. Analytical reliability $\quad$ S39

2.5. Summary $\quad \mathrm{S} 40$

3. Relationship of biomarker to dietary intake (C. Wild, N. O'Brien \& J. Wilson)

3.1. Biomarkers of genistein or daidzein as a marker of 'total' phytoestrogen intake $\mathrm{S} 40$

3.2. Is urinary iodine an indicator of individual intake or at a population level only? S43

4. Relationship of biomarker to natural history of disease (N. O'Brien \& J. Wilson) S44

4.1. Neural tube defects and folate: an example of a narrow time frame of effect $\mathrm{S} 44$

5. Examples of integration of biomarkers into studies of diet and health (C. Andersson, C. Wild, N. O’Brien \& J. Wilson) S45

5.1. Vitamin D and prostate cancer $\quad \mathrm{S} 45$

5.1.1. Biomarkers of vitamin D status $\quad \mathrm{S} 45$

5.1.2. Prostate cancer $\quad$ S46

5.1.3. Biomarkers of vitamin D in studies of prostate cancer $\quad \mathrm{S} 46$

5.2. Cooked meat intake, heterocyclic amines and colorectal cancer $\quad \mathrm{S} 47$

6. Conclusions (C. Wild) S49

\begin{abstract}
One of the problems which may beset epidemiological studies is the difficulty of accurately measuring the dietary intakes of participants. Biomarkers of diet promise to provide a more accurate measure of dietary intake and a more objective one in that they are not reliant on the subject's memory. This review considers some issues of importance in epidemiology when information is obtained from biomarkers. The approach taken is to use examples both of normal dietary constituents and of contaminants in relation to a range of diet and health questions to illustrate these points. A brief overview of the role of sample collection, processing and storage is given including some generic recommendations for maximising the reliability of subsequent analytical data. Using the examples of phytoestrogens and iodine the question of whether biomarkers can accurately reflect the intake of the dietary constituents of interest at the population level or at the individual level is considered. The relationship of the biomarker to the natural history of the disease is exemplified using the role of folate in neural tube defects. Finally, intakes of vitamin D and heterocyclic amines are used to illustrate the integration of
\end{abstract}

Abbreviations: CYP 1A2, cytochrome P450 1A2; HA, heterocyclic amine; 1,25-(OH) 2 - $\mathrm{D}_{3}, 1$, 25-dihydroxyvitamin $\mathrm{D}_{3}$; 25-OH- $\mathrm{D}_{3}$, 25-hydroxyvitamin $\mathrm{D}_{3}$; MeIQx, 2-amino-3,8-dimethylimidazo[4,5-f]-quinoxaline; NAT2, $N$-acetyltransferase-2; PhIP, 2-amino-l-methyl-6-phenylimidazo(4,5-b) pyridine; RIA, radioimmunoassay; T3, tri-iodothyronine; T4, tetra-iodothyronine; TSH, thyroid-stimulating hormone; VDBP, vitamin D binding protein; VDR, vitamin D receptor.

* Corresponding author: Dr C. P. Wild, fax +44 (0) 113233 6603, email c.p.wild@leeds.ac.uk 
biomarkers into epidemiological studies of prostate and colorectal cancer, respectively. It is concluded that biomarkers may provide a more accurate and objective measure of diet than estimates of current or usual intake but that this approach also has limitations. A combination of methods will probably prove to be most valuable and this approach is being taken in current large prospective studies.

\section{Epidemiological studies: Biomarkers: Diet and health: Dietary intake}

\section{Introduction}

Diet has been implicated in a myriad of diseases involving events in the first few weeks of life (folate and neural tube defects) through to chronic illnesses detected predominantly in old age (cancer and cardiovascular disease). For example, at least $35 \%$ of human cancers in developed countries are thought to have a dietary component (WCRF/ AICR, 1997). However, assigning risk of a specific disease to a particular dietary pattern is challenging for a number of reasons. These include, among others, the complexity of diet, the correlation in levels of many nutrients because of their co-occurrence in certain foods and also the possible interactions between diet and either the genetic background of the individual concerned or other environmental factors. An additional problem is the difficulty of accurately measuring dietary intakes in epidemiological studies. Traditionally this has been approached by a combination of methods such as food frequency questionnaires, food diaries, and 24 hour recalls. This information is then combined with food composition tables to calculate intake of specific nutrients. There are recognised limitations to these approaches including problems of poor recall with food frequency questionnaires and inability to account for daily fluctuations in diet in the case of 24 hour recall or food diaries. In addition to problems of mis-reporting, subjects may also unconsciously alter their dietary patterns during the diet recording period.

There can also be a lack of sufficiently detailed information from food composition tables for specific components. For example, these tables have normally been established for nutrients and not necessarily for components of interest in studies of diet and health such as some antioxidant levels. Food composition databases for these are now being established with specific research questions in mind, e.g. for carotenoids, and these can then be combined with food frequency questionnaires to assess intakes (Michaud et al. 1998). Nevertheless, food composition tables may also be inaccurate as pointed out by Riboli et al. (1996) because the same food item may contain different levels of compounds due to natural variations in cultivars or growing conditions. Finally, the dietary factor of interest can be affected by the cooking process and this is again difficult to assess by questionnaire-based approaches and use of standard food composition tables. These limitations have resulted in attempts to use biomarkers in studies of diet and health. The European Prospective Investigation of Cancer (EPIC) is one example of a study collecting detailed questionnaire data but also biological samples from thousands of people across Europe with the goal of investigating the role of diet in health (Riboli, 1992).
Biomarkers of diet promise to provide a more accurate measure of dietary intake and a more objective one in that they are not reliant on the subject's memory when being interviewed or on the accuracy of recording in the food diary. Biomarkers of diet have been categorised into two types by Kaaks et al. (1997): (1) biomarkers which provide an absolute quantitative measure of dietary intakes, e.g. 24-h urinary nitrogen excretion as a measure of 24-h protein intake, this type of marker requires an understanding of the pharmacokinetics of the factor concerned and currently a minority of markers fall into this group; (2) those biomarkers which measure the concentration of a given factor, e.g. plasma vitamins, but for which there is no time dimension to the measurement. Hence the measure correlates with intake but provides no absolute measure of it. The majority of biomarkers of diet are of this type but are nevertheless useful in categorising individuals into relative levels of intake. A further way of classifying biomarkers of diet could be based on whether the markers are of normal dietary constituents (e.g. micronutrients, vitamins, protein etc.) or markers of dietary contaminants (e.g. chemical toxins, microbial agents). With respect to the latter category there are a range of biomarkers of exposure, effect and susceptibility and a number of reviews have considered the properties of these biomarkers (Perera, 1996; Wild \& Pisani, 1997; Hussain \& Harris, 1998).

Despite the potential advantages of biomarkers in studies of diet and health they do not provide a complete answer to the requirement for accurate measurement of dietary intakes. This review considers some of the issues of importance in assessing the information obtained from biomarkers. The approach we have taken is to use examples both of normal dietary constituents and of contaminants in relation to a range of diet and health questions to illustrate these points. We briefly cover the issues of sample collection and processing but the reader is also referred to a recent review on this topic (Landi \& Caporaso, 1997).

\section{Sample collection, processing and storage}

The use of biomarkers in epidemiological studies requires that biological samples should be collected using a suitable protocol and stored, possibly for several years, under conditions that will not result in any alteration of sample composition or deterioration of sample quality. The importance of correct collection, transport and storage procedures can not be over-emphasised, as inadequate control of these factors may result in the production of low quality analytical data. Quality assurance and control 
procedures should also be implemented during the analysis of samples to ensure that reliable data are obtained.

\subsection{Collection}

Once a specific biomarker has been selected for a particular study then collection of samples from study subjects can be carried out with techniques appropriate to the biomarker concerned. However, samples are often banked with the perspective of carrying out future analysis by biomarkers either not specified or fully validated at the time of sample collection. In this case a more generic sampling procedure is required which balances sample availability (e.g. DNA, RNA, proteins, body fluids, etc.) with practical issues of costs and subject acceptability.

It is important that appropriately trained staff carry out the sampling, to ensure safety and also to ensure that relevant samples are obtained. It is at this point that suitable quality control materials should be introduced to the sample to allow the monitoring of sampling and subsequent storage and handling procedures (e.g. Kohlmeier et al. 1997). Safety procedures should be formally implemented wherever possible. For some types of specimens (e.g. blood, urine, tumour tissue), appropriate sample-handling derives from clinical experience, although the treatment of these and other materials (including faeces, exfoliated cells, breast milk, saliva, buccal cells, nail clippings, semen and exhaled air) may require special considerations in an epidemiological setting (Landi \& Caporaso, 1997). Unique identifying codes should be used and the samples should be coded in such a way to ensure that analysts are unaware of exposure status.

\subsection{Transportation}

Where transportation of samples from the sampling point to the laboratory is required, temperature control may be of importance. Kohlmeier et al. (1997) placed subcutaneous adipose tissue samples on dry ice immediately after collection and maintained these conditions during transport. These workers also included quality control samples which were transported with the test samples. In order to ensure that correct identification of the samples is maintained, tamper-proof containers may also be considered and a labelling system which is unaffected by low temperature (e.g. dry ice or liquid nitrogen). The transport conditions and timing should be recorded. In the case where samples are transported across national borders in the context of multicentre studies then safety declarations and import regulations should be addressed in advance.

\subsection{Storage}

Due to the potentially labile nature of some analytes, as well as the timescale of epidemiological studies, close attention must be paid to the processing and storage conditions used. The processing of biological samples prior to storage may be considered in order to reduce analysis time later or to improve the stability of the analyte. Where blood is sampled, it can either be frozen immediately or after separating it into its component parts, e.g. white blood cells, lymphocytes, platelets, red blood cells, haemoglobin, plasma, serum, DNA, proteins, etc. Urine can be stored whole or, if appropriate, centrifuged to allow exfoliated cells to be separated and stored.

In order to develop robust protocols, storage trials should be carried out to determine whether analytes undergo decomposition over time. Examples of such trials were undertaken by Key et al. (1996) who investigated whether storage at $4^{\circ} \mathrm{C}$ overnight caused significant changes in whole blood, and Evans et al. (1996) who examined the effects of storage on the levels of lipoprotein(a) in serum over three years, with the samples kept at either $-20^{\circ} \mathrm{C}$ or $-70^{\circ} \mathrm{C}$. This type of control has also been conducted on the biological bank from the Malmo Diet and Cancer Study involving in excess of 30000 subjects (Pero et al. 1993). A range of bioassays were used to check the effects of storage on mononuclear leucocyte viability and response to mitogens, DNA strand breakage in granulocytes, erythrocyte lysis and reactive thiol levels as an indicator of plasma stability (Pero et al. 1998a). In the case of leucocytes the reduction in growth response after 40 weeks' storage led to a change in the protocol for sample processing. It is also important in prospective studies to consider obtaining pathological specimens from subjects in the cohort as this may permit further studies of aetiology by linking markers of exposure with molecular alterations in tumours from the same individuals (Pero et al. 1998b; Hussain \& Harris, 1998). In multicentred studies, consideration should be given as to whether the samples should be transferred to a central storage area or kept at the collection centres. If the latter option is chosen, suitable standardisation protocols and quality control procedures should be implemented, for example the monitoring of freezer temperatures, to guard against variability in analytical data resulting from different storage conditions.

\subsection{Analytical reliability}

The amount of effort expended on the quality control and quality assurance procedures is determined by the required sample throughput and the complexity of the biomarker assay (Gompertz, 1997). General quality control procedures should include appropriate staff training and the use of formal laboratory protocols, including statistical quality control procedures (coefficient of variance, standard deviation and inaccuracy limits for data) (Westgard et al. 1991) and the calculation of inter- and intrabatch variation. Analytical reliability checks include the routine analysis of suitable certified reference materials, or the production of an in-house reference material. Cocker et al. (1996) for example produced stable and standardised freeze-dried samples of urine using methylene bis(2-chloroaniline).

If suitable certified reference materials are unavailable, it is recommended that quality control procedures should include participation in collaborative trials (Gompertz, 1997). Participation in quality assurance schemes allows laboratories to identify potential problems in analysis and thereby improve analytical quality. These schemes can be run internally, as described by Bennett et al. (1993) or externally, such as that run by the Belgian Epidemiology Unit of the Institute of Hygiene and Epidemiology for the 
analysis of metals (lead, cadmium and selenium) in blood (De Plaen et al. 1996). Cocker et al. (1996) also prepared spiked samples that were extracted within each analytical batch in order to allow quantification of the efficacy of their analytical method by determination of analyte recovery.

Internal standards are another important quality assurance procedure which can allow the analyst to accurately assess the quality of the data produced. Internal standards can be labelled (Friesen et al. 1994) or homologous (Ganguly et al. 1996) forms of the analyte under study or compounds of similar chemical behaviour.

When measurements are near or at the limit of detection, greater attention should be paid to monitoring analytical stability. This may require additional duplicate analyses. Where new methods are being introduced, comparisons against data obtained using previously validated methods should be carried out. An example of this is where Frerichs et al. (1994) collected saliva and plasma samples from volunteers and analysed them separately by a method previously validated only for the analysis of plasma. The results were compared and it was concluded that the method was valid for both types of biological sample.

\subsection{Summary}

In order to ensure that biomarker samples for use in epidemiological studies are collected, stored and analysed to the highest quality, the following points should be considered.

- Appropriately trained staff must carry out the sampling to ensure the safety of operators and to ensure that relevant samples are obtained.

- Suitable quality control samples should be introduced at an early stage to allow the monitoring of sampling and subsequent procedures.

- Unique identifying codes should be used and the samples should be coded in such a way that analysts are unaware of exposure status.

- Temperature control should be maintained as samples are transported.

- Trials should be carried out to determine whether analytes undergo decomposition during storage.

- If the study is multicentred, consideration should be given as to whether the samples should be transferred to a central storage area.

- Suitable standardisation protocols and quality control procedures should be implemented to guard against variability in analytical data if samples are kept at different sites.

- Sufficient staff training should be given in the use of formal laboratory protocols and analytical methods.

- Routine analysis of suitable certified reference materials or in-house reference samples should be carried out.

- Participation in collaborative trials is desirable if suitable certified reference materials are unavailable.

- Spiked samples and internal standards should be used.

- Comparisons are desirable between the results obtained using new procedures and those from validated methodology.
- Participation in quality assurance schemes allows analytical problems to be identified.

\section{Relationship of biomarker to dietary intake}

One of the basic requirements of a biomarker is that it accurately reflects intake of the dietary constituents of interest. These types of validation studies in practice have often been conducted using relatively small numbers of subjects either to use the biomarker to validate a questionnaire assessment of intake, e.g. for carotenoids (Michaud et al. 1998) or to validate the biomarker in relation to precise measurement of dietary intake at the individual level, e.g. for aflatoxins (Wild et al. 1992). However, for dietary nutrients validation can often be a complex issue. In some cases the 'constituent' of interest may in fact be a mixture of compounds with similar biological mechanism of action, e.g. endocrine disrupters or antioxidants, in which case the question arises as to whether 'total' content of these compounds should be measured or whether there are sentinel biomarkers which are representative of the class of compounds. In addition, it may not be the compound itself as found in the diet which exerts an effect at the cellular level but rather a metabolite in which case it may be more relevant to focus on biomarkers of the latter. Indeed, absorption of a given component may differ across individuals, an example of this being with lycopene (Stahl \& Sies, 1992) or bioavailability can be affected by other dietary factors, e.g. fat and carotenoids or host factors (Beecher \& Khachik, 1992) all of which can modify the correlation between intake and biomarker. Furthermore, biomarkers may provide a picture of dietary status at the population level but be so variable over a short time period in an individual that they provide little information in this regard. This section illustrates a number of these points using the examples of phytoestrogens and iodine.

\subsection{Biomarkers of genistein or daidzein as a marker of 'total' phytoestrogen intake}

Hormones are believed to influence a number of diseases of which breast cancer and prostate cancer are two examples. Several epidemiological studies have suggested that consumption of a phytoestrogen-rich diet (particularly soy), or carrying high levels of phytoestrogens in serum or urine, are associated with a low risk for developing these types of cancer due to the hormonal activity of phytoestrogens (Adlercreutz, 1993). Recently, it has also been suggested that diets rich in isoflavone phytoestrogens could play a role in prevention of other oestrogen-related diseases or conditions, namely cardiovsascular disease, osteoporosis and menopausal symptoms (Tham et al. 1998) but actual proof that phytoestrogens have these effects are still missing. There are also health concerns regarding fertility at high phytoestrogen intake (Humfrey, 1998).

The question of the impact of phytoestrogens on human health is an important one where epidemiological data are required to permit a full assessment. The use of biological specimens in epidemiological studies of phytoestrogens is 
of particular interest because assessment of dietary intake is currently limited by the paucity of quantitative data on the content of most phytoestrogens in individual foods. But there are several reasons why it is problematic to develop biomarkers for these compounds. Problems include the diversity of compounds classed as phytoestrogens, the kinetics of their uptake, distribution, metabolism and excretion, the variety of biological effects they exert and the range in potency between compounds exerting these effects. These issues are discussed briefly below as an example of assessing exposure to complex mixtures in the diet.

Phytoestrogens are non-steroidal, often diphenolic plant compounds. The majority of phytoestrogens found in human diets can be categorised into two primary classes, isoflavones and lignans. The two major isoflavones found in humans (also the most common form of phytoestrogens) are the aglycones, genistein and daidzein, which are metabolic products from their plant precursors, biochanin $\mathrm{A}$ and formononetin, respectively. The isoflavones in nonfermented soy foods are mostly present as beta-glucosides, some of which are esterified with malonic or acetic acid. In fermented soy foods, the isoflavones are largely unconjugated (Barnes, 1999). The unconjugated isoflavones are probably absorbed quickly and efficiently from the upper small intestine, whereas the isoflavone glycoside conjugates are absorbed more slowly, consistent with their being hydrolysed at more distal sites in the intestine to unconjugated isoflavones by the intestinal microflora. Since the fermentation takes place in the large intestine, and the metabolites are enterohepatically circulated, it generally takes some time (at least 6-8 h) after food consumption before they can be measured in body fluids and excreta. If the colonic microflora is competent, daidzein may be further metabolised to equol or $O$ demethylangolensin, and genistein to $p$-ethyl phenol.

Lignans are an important part of lignin in the plant cell wall. The plant lignans differ somewhat from mammalian lignans. The main lignans excreted in humans are enterolactone and enterodiol, which are metabolites of the plant lignans matieresinol and secoisolariciresinol, respectively. Enterodiol may be oxidised to enterolactone. The mammalian lignans also undergo enterohepatic circulation. The fate of many phytoestrogens once ingested remains unclear since only a fraction of the ingested dose is excreted in urine (or faeces).

Although data are still sparse, information has started to accumulate in the literature on the occurrence of phytoestrogen precursors in foods (Mazur, 1999). Commonly investigated phytoestrogens in biological fluids, such as isoflavonoids and biotransformed lignans, are derived mainly from Fabaceae-based foods and oilseeds (including soy, lupin, peanut, fenugreek, lentil and pea), and from cereals and whole grain, respectively. However they are also found in berries and currants, fruits, onions, other vegetables, and beverages, such as red wine (Kopp, 1998; Mazur, 1999). The highest concentrations of phytoestrogens in the human diet are the isoflavones in soy food and the lignans in flaxseed and linseed (Price \& Fenwick, 1985; Reinli \& Block, 1996). However, other groups of phenolics also have phytoestrogenic activity including the flavonoids, chalcones and coumestans but for many of these good methods are not yet available for their quantification in biological fluids. In addition, although a substantial number of phytoestrogens have been identified in plants, it seems probable that many have not yet been identified which could also contribute to the biological effects related to health outcomes. This complexity makes it difficult to comprehensively assess human exposure and raises the question as to whether measurement of a few compounds would provide a true representation of the diet's phytoestrogenic activity?

A further problem in developing biomarkers for phytoestrogens is that the critical mechanism of action of phytoestrogens with respect to health effects in humans is still under discussion. Phytoestrogens have weak oestrogenic and anti-oestrogenic effects in mammalian tissues. For isoflavone and coumestan-type phytoestrogens (such as genistein and coumestrol) it has been well documented that they act as oestrogens, i.e. bind to oestrogen receptors and transactivate oestrogen-responsive genes in vitro (Mäkelä et al. 1998). Until recently isoflavonoids were best known for the reproductive disturbances they cause in livestock and experimental animals (Humfrey, 1998). As phytoestrogens are weak oestrogens, it has been suggested that they would act as anti-oestrogens, i.e. compete with the more potent endogenous oestrogens for binding to ER, but this is not supported by the findings in in vitro conditions or in vivo in experimental animals (Mäkelä et al. 1998). The identification and cloning of a second and novel oestrogen receptor (Kuiper et al. 1996), referred to as $\operatorname{Er} \beta$, with its unique anatomical distribution in tissues such as bone, brain, vascular endothelia, and bladder and its ligand specificity toward phytoestrogens further complicates our understanding of steroid hormone action. Furthermore, experimental studies have shown that phytoestrogens have multiple mechanisms of action, of which hormonal signal transduction (oestrogen-like effects) is only one. For example, several flavonoid and coumestan type phytoestrogens are reported to inhibit steroid-biosynthesising enzymes or to increase the production of sex hormone binding globulin in vitro and isoflavones inhibit protein tyrosine kinases, DNA topoisomerases and angiogenesis (Adlercreutz, 1995; Tham et al. 1998). Several flavones can act as antioxidants in vitro and possibly in vivo. For example, a small study on men who consumed 1 litre of soy milk per day for four weeks, revealed significantly elevated plasma levels of genistein and daidzein and decreased DNA damage in lymphocytes, as compared to men who consumed 1 litre of rice milk per day for four weeks (Mitchell \& Collins, 1998). The reduction in DNA damage would perhaps be more easily explained by the isoflavones having an antioxidant effect rather than an anti-oestrogenic effect. Thus, by reducing DNA damage as antioxidants the phytoestrogens could have a chemopreventive role in cancer whereas the oestrogenic activities could either protect against or promote cancer risk. Of course the ranking of phytoestrogens with respect to these diverse biological activities will be different for each activity. Furthermore, it is possible that phytoestrogens interact with other phytoestrogens, synthetic oestrogens and natural endogenous oestrogens in vivo. Currently, the fact that 
none of the above actions have been demonstrated in vivo, and the concentrations required in vitro are generally much higher than those reported in human or animal serum severely complicates identifying good biomarkers for epidemiological studies.

The questions discussed above of complexity of phytoestrogen exposure and their biological activities are further complicated by the difficulties in analytical methodologies (e.g. requirement of mass spectrometry). Of the phytoestrogens identified only some are commercially available for study and indeed a drawback at the present time is that the analytical methods for their detection are still poorly standardised and validated. Since purified compounds are required as standards both in chemical analytical studies determining their levels in food products, and in biological fluids, it is obvious currently that it is only possible to quantify a limited number of the plant-derived oestrogenic and anti-oestrogenic compounds.

Few studies have measured circulating concentrations of phytoestrogens - a reflection of the greater difficulty of measuring these compounds in plasma/serum compared with urine (Setchell, 1998). Only one pilot study has been performed to assess reliability of serum measurements of lignans and isoflavonoid phytoestrogens in healthy subjects (Zeleniuch-Jacquotte et al. 1998). The result of the study was discouraging. It revealed high coefficients of variation in analytical data, a small proportion of high values, low reliability coefficients of serum levels of isoflavonoids in the subjects studied, and indicated that the study design was not well suited to examine the relation between serum isoflavonoids and disease risk. Instead of using plasma/ serum, researchers have focused on measuring phytoestrogens in complete 72-h urine samples (sometimes only 48-h samples). Understandably, these are somewhat impractical biomarkers in epidemiological studies, risking high dropout rates. This long period of collecting urine gives an index of phytoestrogen consumption and metabolism over 4-5 days (Ingram, 1998). An important question is whether a single measurement of urinary phytoestrogens provides a reliable measure of exposure during the relevant time period for disease development.

In general, measurements of urinary diadzein, genistein, or their metabolites provide a useful indicator of compliance with a diet containing soyfoods. A positive correlation has been observed between the intake of soyor plant-based food and the urinary excretion of isoflavones (Adlercreutz et al. 1991; Cassidy et al. 1994; Xu et al. 1994, 1995; Baird et al. 1995; Hutchins et al. 1995; Kirkman et al. 1995; Lu et al. 1995, 1996; Karr et al. 1997; King \& Bursill, 1998; Slavin et al. 1998; Watanabe et al. 1998; Chen et al. 1999; Zhang et al. 1999), but the recovery of isoflavones in urine is generally limited (less genistein is recovered than daidzein), probably because the compounds are degraded and metabolised by the intestinal microflora. Faecal excretion of the isoflavonoids is low (Xu et al. 1994). At higher doses the absorption, as reflected by urinary excretion, may be saturated. Another common finding in these studies is the high inter- and intraindividual variability in urinary excretion of isoflavones among subjects consuming soy- or plant-based foods (Franke \& Custer, 1994; Baird et al. 1995; Lu et al. 1995, 1996; Lu \&
Anderson, 1998; Setchell, 1998; Watanabe et al. 1998; Chen et al. 1999; Zhang et al. 1999). Depending on the level of the intake of soy and the compound looked for, the variation observed has been up to 180 -fold. The reason for this variability is unclear, but it could partly be explained by significant interindividual differences in absorption and a highly variable metabolism inter- and intraindividually over time. This fact adds another aspect to the question whether a single urine sample is enough to describe phytoestrogen exposure. In accordance with these observations, Setchell and co-workers showed that the pharmacokinetics of a single bolus oral administration of the pure compounds daidzein, genistein, daidzin, and genistin varied between adult persons. In women, peak concentration $\left(C_{\max }\right)$ varied 10 -fold between individuals (80-800 ng/ml), the time to reach $C_{\max }$ generally being between 6 and $8 \mathrm{~h}$ after ingestion (Setchell, 1998). There is general consensus that no more than $30 \%$ of the ingested dose of isoflavone can be accounted for in the urine (Franke \& Custer, 1994; Xu et al. 1994). Interestingly, about one-third of healthy subjects are unable to metabolise daidzein to equol and $O$-desmethylangolensin. The urine of these individuals contains much higher concentrations of the precursors. The lack of ability to metabolise daidzein is probably due to variability between individuals in dietary habits leading to differences in the gut flora known to be responsible for the isoflavone biotransformation. Therefore, the levels of both dietary isoflavonoids and their metabolites must be determined in order to assess exposure to soy foods correctly.

Fewer studies have been published on lignan availability in humans. Lignan excretion was studied in American, Finnish, and Japanese populations with a range in diet from the 'Western' omnivorous to semivegetarian, vegetarian, and macrobiotic. It was found to be very high in the vegetarians and in subjects consuming large amounts of whole-grain products, vegetables, fruits, berries, and flaxseed (Adlercreutz et al. 1982, 1986, 1991, 1993; Herman et al. 1995). Accordingly, when an omnivorous diet was supplemented with flaxseed the excretion of enterodiol and enterolactone was large (Lampe et al. 1994; Cunnane et al. 1995), as was the variation between subjects (between a 3 - and 285-fold increase). These studies also indicated that flaxseed lignans are metabolised at a slower rate than soybean isoflavones, and that there is a linear doseresponse in urinary excretion of lignans (Morton et al. 1997; Nesbitt et al. 1999).

Whereas the data for an effect of sex on isoflavonoid excretion is contradictory (Adlercreutz et al. 1991; Lu et al. 1995, 1986; Lu \& Anderson, 1998; Kirkman et al. 1995), sex differences have been observed for lignan excretion (Kirkman et al. 1995). Men excreted more enterolactone and less enterodiol than women, implying a sex difference in colonic bacterial metabolism of lignans. Another factor that influences phytoestrogen excretion in urine is the race/ ethnicity of the individual (Horn-Ross et al. 1997), possibly reflecting different diets. The highest levels of coumestrol and lignan metabolites were observed in white women, whereas the lowest levels were found in Latin and African American women. Genistein levels, however, were highest 
in Latin women. Excretion of the other isoflavones investigated did not differ significantly by race/ethnicity.

Taken together, the information given above indicates that it is unlikely that an accurate measurement of any specific phytoestrogen could represent phytoestrogen intake at the level of the individual. Two studies have tried to validate urinary phytoestrogen biomarkers by comparing the level of excretion with the intake of phytoestrogens as revealed by information from food frequency questionnaires. In a Chinese study on women from Singapore, a positive correlation was observed at the group level between usual frequency of soy food intake over the past 12 months and urinary isoflavonoid excretion in a spot urine sample, but not at the individual level (Seow et al. 1998). Chen et al. (1999) correlated the usual soy food consumption (i.e. the consumption in the previous five-year period) with the urinary excretion of isoflavonoids in overnight urine samples of 60 healthy women in Shanghai. In this population with a very high soy food intake the individual urinary excretion rate of total isoflavonoids measured from overnight urine samples reflected reasonably well the usual intake of soy foods. The correlation to the actual intake shortly before urine samples were collected was unfortunately not investigated in this study.

\subsection{Is urinary iodine (I) an indicator of individual intake or at a population level only?}

The only known role of the essential micronutrient iodine in the body is for the synthesis of the thyroid hormones, thyroxine or tetra-iodothyronine (T4) and tri-iodothyronine (T3), which help regulate a wide range of physiological processes (Clugston \& Hetzel, 1994; Hurrell, 1997). Iodide is taken up from the intestinal tract and transported in the body bound to plasma proteins. The necessary amount is removed from the plasma by the thyroid for hormonal synthesis, and the remainder is excreted by the kidney. Urinary excretion is the major route of elimination from the organism, the other routes being quantitatively negligible (Stansbury, 1988).

Dietary iodine deficiency results in decreased plasma levels of $\mathrm{T} 4$ and $\mathrm{T} 3$ and a compensatory increase in thyroid stimulating hormone (TSH) secretion as well as reduced iodide excretion. To increase iodine uptake at limited intake, TSH increases thyroid cell size and cell number and the gland enlarges to form a goitre. This is the main effect of iodine deficiency and consequently goitre incidence (200 million people worldwide) is a frequently used indicator of the iodine status of a population (Lamberg, 1993). However, goitre can also be produced by other mechanisms, e.g. by goitrogenic substances, and therefore goitre itself is not a specific biomarker for iodine deficiency. In addition, iodine deficiency may also result in other effects on growth and development of the fetus, neonates, children and adults, particularly of the brain causing mental retardation, and these are grouped as iodine deficiency disorders (Clugston \& Hetzel, 1994; Hurrell, 1997).
There are several types of biomarkers used in epidemiological investigations to evaluate iodine status and exposure. Since the majority of dietary iodine is excreted in urine (usually over $90 \%$ of the daily intake) and only a minor fraction in faeces, urinary iodine is a widely used biochemical marker of iodine status (Lamberg, 1993; Thomson et al. 1996; Dunn, 1993). The principles of urinary iodine methods have been reviewed by Dunn (1993), as have the problems with other indicators of iodine status; thyroid size by palpation is difficult when the goitres are not large, ultrasound assessment of thyroid size is accurate and feasible in the field but requires skilled operators, neonatal TSH screening is of limited use unless it is universal within a population, whereas laboratory measurements of serum thyroid hormones give less information at more cost.

The iodine content of foods varies considerably with relatively few foods having a high content of iodine and some foods varying significantly from batch to batch (Møller, 1996). Therefore, the intake of iodine will vary greatly within a day, from day-to-day and from person to person, as will the daily iodine excretion (Brug et al. 1992; Thomson et al. 1996; Dunn, 1993; Rasmussen et al. 1999) which is $85-90 \%$ dependent on the iodine intake. Since there is no agreement on whether there is a circadian periodicity, seasonal variation and sex difference in iodine excretion, these factors also have to be considered in the experimental situation. The easiest urinary samples to collect in epidemiological studies are single void specimens (with or without fasting), but these are also the ones most vulnerable to the natural variation in iodine intake and excretion. To reduce the variation in iodine excretion in single void urine samples, it has been suggested to express the iodine excretion as a concentration (Bourdoux, 1993) or as the ratio between urinary iodine and urinary creatinine, assuming creatinine excretion to be constant. However, these methods are without value in areas where large interand intraindividual variation in urinary creatinine excretion exist, and, therefore, not the most suitable index for assessing iodine status (Bourdoux, 1993; Thomson et al. 1996, 1997).

Although 24-h urine samples are both inconvenient for the subject and difficult to collect accurately, they are normally considered to be the most reliable specimen for assessing iodine status of an individual, especially for research purposes (Hetzel \& Dunn, 1989; Gibson, 1990; Thomson et al. 1996, 1997). Because of the day-to-day variation in iodine excretion, Rasmussen et al. (1999) have suggested that the average of more than one 24-h urine sample should be used to determine the iodine status of an individual.

In the absence of other more-stable practical biomarkers than urinary iodine to measure the iodine status, it has been argued that fasting urine samples, but not casual single void samples, give a reasonable estimate of urinary iodide excretion on a population basis, but that 24-h urine samples are preferable for assessment of the iodine status of individuals. As stated above, the average of repeated 24-h urine samples would be still more preferable for estimating an individual's habitual high or low excretion. 


\section{Relationship of biomarker to natural history of disease}

The relationship between the timing of the biomarker measurement and the natural history of the disease process is fundamental to interpreting epidemiological data. Biomarkers of diet generally reflect recent intakes and therefore assumptions need to be made as to how current measurements reflect past diet; this has led to a search for measures of long-term past exposure. There are exceptions to the short-term nature of biomarkers with for example the stability of fat-soluble nutrients or pesticides in adipose tissue (Stellman et al. 1998; Su et al. 1998). Su et al. (1998) compared levels of carotenoids and tocopherols in plasma and adipose tissue and showed a significant degree of variation in some compounds for a given individual suggesting that these biomarkers are not interchangeable. In contrast, the studies of pesticides showed a good correlation at the individual level between measures in serum and adipose tissue (Stellman et al. 1998). A further concern, at least in the classic case-control study design where biological samples can only be collected at the time of diagnosis, is that biomarker measurements may be compromised in cases either because disease causes a change in dietary habits (e.g. reduced appetite) or because the disease process affects the pharmacokinetics of the biomarker. Prospective cohort studies should resolve this problem but consideration should still be given to the possible effects of undiagnosed preclinical disease on biomarkers. In addition to these considerations it is possible that the diet influenced disease risk at a specific stage in the disease process. For example, nasopharyngeal carcinoma in southern China has been associated with salted fish intake but the risk appears to be particularly associated with intake early in life ( $\mathrm{Yu}$ et al. 1986). In this instance the putative carcinogen in the fish preparation may exert its effects at an early stage of carcinogenesis, one for which it is highly unlikely that an appropriate biomarker would become available, and therefore questionnaire data may be more reliable. Indeed biomarkers of intake of this component in adulthood would probably result in an underestimation of risk. An extreme example where diet affects health in a narrow time frame is folate and neural tube defects.

\subsection{Neural tube defects and folate: an example of a narrow time frame of effect}

Most defects of the spinal cord result from abnormal closure of the neural folds (neural tube defects) during the second half of the first month of development, predominantly between days 22 and 26 after conception (Larsen, 1993). There are studies indicating that women that have given birth to a child with neural tube defects have lower folate status (folic acid and its carbon substitutes and polyglutamate forms found in food) and higher homocysteine status than the control group at the time in pregnancy when neural tube defects occur (Mills et al. 1996) and that intervention with multivitamins reduced dramatically the risk of neural tube defects in subsequent pregnancies (Smithells et al. 1980, 1983). A substantial number of observational case-control studies based on interviews linked a low total folate intake to an increased risk of giving birth to children with neural tube defects (Duff \& Cooper, 1994; Rush, 1994; de Bree et al. 1997). The interpretation of a role for folate deficiency has been strengthened by randomised controlled clinical trials with folic acid (MRC Vitamin Study Research Group, 1991; Werler et al. 1993; Czeizel, 1995). The time period of pregnancy identified as important in these studies is the periconceptional period. Unfortunately, there are no longitudinal studies which show the variability for an individual over time. Folate has two known important biological effects. It is required in the transfer of methyl groups in the amino acid methylation cycle (particularly recycling of homocysteine to methionine), and is a cofactor providing single carbon units for de novo synthesis of nucleotide bases. Because nucleic acid and protein synthesis are at their peak during embryogenesis and rapid fetal growth, maternal folate requirement increases dramatically during this time. However, the exact mechanism by which folate exerts its protection against neural tube defects is not well understood (Locksmith \& Duff, 1998).

Sometimes it is difficult to identify whether inadequate dietary folate is the main risk factor for neural tube defects or whether it is folate deficiency resulting from effects in the body, e.g. a disturbance in folate metabolism (Mills et al. 1996; Fleming \& Copp, 1998; Bailey \& Gregory, $1999 a$ ), or poor absorption due for example to drug action, alcoholism or smoking. An importance of the metabolic machinery for the development of neural tube defects was recently indicated by the observation that genetic polymorphisms of key enzymes of one-carbon metabolism not only resulted in mild hyperhomocysteinaemia and redistribution of folates, but also were identified as a risk factor for neural tube defects (Bailey and Gregory, 1999a,b). Further studies are required to explore this possibility.

The extremely narrow timeframe during which neural tube defects occur during development poses particular problems for biomarker applications because, ideally, studies should examine the folate status of women during weeks 3-5 of fetal development. This may be feasible in specifically designed large-scale prospective studies or intervention studies but is certainly more problematic in most epidemiological studies, and particularly in traditional case-control designs where the ability to measure folate status several weeks or months earlier would be required depending on time of diagnosis. Three biomarkers for folate have been popular until now, plasma/serum folate, red cell (erythrocyte) folate and plasma/serum levels of homocysteine.

Measurement of the plasma/serum levels of folates appears to be the least suitable biomarker for folate exposure in relation to induction of neural tube defects, because plasma/serum folate is sensitive to changes in intake or temporary changes in folate metabolism, and in addition is unstable in this matrix. Thus, measurement in a single sample merely reflects the transient concentration of the vitamin between absorption and utilization or storage, i.e. it provides reliable information only for the previous 24 hours (Kohlmeier, 1995). Consequently if this biomarker is used in prospective epidemiological studies on neural tube defects, it implies that a large series of blood samples has to 
be collected to ensure that the crucial time period for occurrence of neural tube defects is covered, since it is impossible to determine time of conception beforehand.

Erythrocyte folate levels are about 20 times the concentration of plasma/serum folate and appear to be a better biomarker since they reflect body stores and are considered to be a measure of long-term folate status. Red blood cells incorporate folate at erythropoiesis and retain it during their life span (Shane, 1995). Thus, red cell folate reflects the folate turnover during at least the previous three months (Krumdieck et al. 1978; Kirke et al. 1993; Stites et al. 1997). Unfortunately, there are methodological problems with the analysis of red cell folate by both microbiological and protein-binding methods - they have been criticised for poor reproducibility (Gunter et al. 1996). Another drawback is that the erythrocyte folate biomarker is non-specific in the sense that it is also reduced by vitamin $B_{12}$ deficiency so that the marker may not reflect intake but could still reflect bioavailability. Nevertheless, some studies have shown that red cell folate levels, rather than serum folate levels, are lower in women who give birth to infants with neural tube defects (Smithells et al. 1976; Slattery \& Janerich, 1991). This finding may indicate that red cell folate levels are more sensitive to a range of deficiencies than are serum folate levels (Herbert \& Colman, 1988). It should be noted, however, that despite the advantages of erythrocyte folate levels in indicating recent past folate status for other types of study, e.g. when studying the short-term effects of supplements or in the evaluation of bioavailability, there is actually a need for additional functional tests, sufficiently sensitive and specific, to reflect rapid changes of folate status.

A further consideration in folate analysis is that they occur as complex mixtures and individual folates may have different biological activity. Therefore, it would be preferable to be able to refine biomarker measurements by distinguishing between compounds having different biological activity. The best way to measure folate is probably by HPLC after converting the natural polyglutamates into the monoglutamate derivatives.

The third biomarker for folate status is plasma/serum levels of homocysteine. The incentive to study this biomarker in studies on neural tube defects is that several studies have shown that plasma homocysteine is an early indicator of intracellular folate deficiency. The homocysteine levels are significantly elevated at reduced folate levels (Mills et al. 1995) However, this indirect biomarker has the same drawback as plasma/serum folate, requiring a longitudinal series of blood samples to ensure that the crucial time period of neural tube defect induction is covered. The total blood level of homocysteine is fairly quickly reduced by vegetable and citrus fruit rich diet (foods also rich in folate), and by supplementation of the diet with folic acid (Jacob et al. 1994; O'Keefe et al. 1995; Ward et al. 1997; Brouwer et al. 1999a,b). However, interpretations from serum homocysteine concentrations have to be made with care since the homocysteine concentration has been shown not only to be a sensitive functional indicator of intracellular folate but also for vitamin $B_{12}$ and $B_{6}$ status and hence again the question of specificity of the marker is raised.

\section{Examples of integration of biomarkers into studies of diet and health}

In the following sections two more complete examples are given to illustrate how biomarkers can be integrated into the study of diet and human disease. The first example concerns an essential vitamin, vitamin $\mathrm{D}$, in relation to prostate cancer risk. This example raises issues about which is the biologically active form of the vitamin, the stability of the biomarkers of intake and the influence of genetic polymorphisms of binding to a receptor. The second example concerns a group of carcinogens, the heterocyclic amines, which are dietary contaminants. In this example issues of internal dose, biologically effective dose, genetic susceptibility and determination of long-term past exposure are explored.

\subsection{Vitamin D and prostate cancer}

5.1.1. Biomarkers of vitamin D status. Vitamin D exists in two basic forms, i.e. vitamin $\mathrm{D}_{3}$ (cholecalicferol) and vitamin $\mathrm{D}_{2}$ (ergocalciferol). Vitamin $\mathrm{D}_{3}$ is the predominant form in humans and is synthesised in the skin from 7dehydrocholesterol following UV light exposure and can also be obtained from dietary sources. Vitamin $\mathrm{D}_{2}$ has similar metabolic behaviour to vitamin $\mathrm{D}_{3}$ and is obtained exclusively from dietary sources. Both vitamin $\mathrm{D}_{3}$ and $\mathrm{D}_{2}$ are transported in the bloodstream non-covalently bound to vitamin $\mathrm{D}$ binding protein (VDBP).

The liver and kidney are the principal sites of metabolic activation of vitamin D. Vitamin $\mathrm{D}_{3}$ is hydroxylated in the liver to 25-hydroxyvitamin $\mathrm{D}_{3}\left(25-\mathrm{OH}-\mathrm{D}_{3}\right)$, also known as calcidiol, which is the principal circulating metabolite of vitamin $\mathrm{D}_{3}$. Circulating $25-\mathrm{OH}-\mathrm{D}_{3}$ levels are considered to be a reflection of the bioavailability of vitamin $\mathrm{D}_{3}$ and the best biomarker of vitamin D status and intake (Holick, 1990). The liver has excess capacity to convert vitamin $D_{3}$ into $25-\mathrm{OH}-\mathrm{D}_{3}$ and the biological half-life of the latter metabolite is several weeks. Serum levels of $25-\mathrm{OH}-\mathrm{D}_{3}$ are generally higher in summer than in winter especially at northern latitudes. Normal levels are in the range $8-60 \mathrm{ng} / \mathrm{ml}$ and are not tightly regulated. Measurements of $25-\mathrm{OH}-\mathrm{D}_{3}$ by HPLC, is quite a reliable biomarker of vitamin D status as there is not much intraindividual variation on a time basis within a particular season (HF DeLuca, personal communication).

$25-\mathrm{OH}-\mathrm{D}_{3}$ is bound to an alpha-2 globulin in plasma and transported to the kidney where it undergoes a second hydroxylation step to generate 1,25-dihydroxyvitamin $\mathrm{D}_{3}$ $\left[1,25-(\mathrm{OH})_{2}-\mathrm{D}_{3}\right]$, also known as calcitrol (Basu \& Dickerson, 1996). This dihydroxylated form of vitamin D is the active metabolite involved in stimulation of intestinal calcium and phosphate transport and bone calcium mobilisation. Only a small percentage of $25-\mathrm{OH}-\mathrm{D}_{3}$ is hydroxylated to $1,25-(\mathrm{OH})_{2}-\mathrm{D}_{3}$ which has a biological halflife of $4-6 \mathrm{~h}$ and levels are closely regulated within the range $16-60 \mathrm{pg} / \mathrm{ml}$ (Holick, 1990). 1,25-(OH $)_{2}-\mathrm{D}_{3}$ is the hormonal form of vitamin $\mathrm{D}$ and its level is modulated by factors including vitamin D status, parathyroid hormone level, and blood phosphate levels. Thus, it is more a biomarker of physiological status than of vitamin D status. 
Single measurements per individual of $1,25-(\mathrm{OH})_{2}-\mathrm{D}_{3}$ are not a good index of vitamin D status because of the short half-life. A second hydroxylated metabolite of vitamin D, 24,25-dihydroxyvitamin $\mathrm{D}\left[24,25-(\mathrm{OH})_{2}-\mathrm{D}_{3}\right]$ is also produced in the kidney but has limited biological activity and no certain function has been attributed to it.

Vitamin D binding protein (VDBP) is a relatively poor biomarker of vitamin $\mathrm{D}$ status as it is generally stable within an individual over time even when there are changes in vitamin D intake or sunlight exposure; an exception would be conditions of protein deprivation. Genetic polymorphisms in the vitamin $\mathrm{D}$ receptor (VDR) are obviously not a biomarker of individual vitamin D status but may affect the relationship between vitamin $\mathrm{D}$ levels and disease.

5.1.2. Prostate cancer. Cancer of the prostate is a common malignancy particularly in Western countries (IARC, 1992; Parker et al. 1996). Incidence rates differ markedly between different ethnic groups with AfricanAmerican men having the highest incidence and Japanese and Chinese men the lowest rates (IARC, 1992). USA data indicate higher prostate cancer rates in the north of the country compared to the south giving rise to the hypothesis that UV exposure may be a risk factor for prostate cancer (Hanchette \& Schwartz, 1992). As discussed above, most of the body's supply of vitamin D is synthesised in the skin in response to UV exposure. Thus a number of epidemiological studies have been conducted in recent years investigating the relationship between biomarkers of vitamin D status and prostate cancer risk.

5.1.3. Biomarkers of vitamin $D$ in studies of prostate cancer. A key methodological problem in interpreting biomarker data versus disease outcome lies in the relative time interval between the two measurements. For example, if the biomarker (e.g. blood $25-\mathrm{OH}-\mathrm{D}_{3}$ ) is measured at the time of disease diagnosis (e.g. prostate cancer), the issue of cause and effect clearly arises. The obvious question is how long prior to the onset of the disease state should data on the biomarker be obtained? Diseases such as prostate cancer may have a very long genesis period of up to several decades. There are no firm data indicating the optimum timepoint at which to measure the biomarkers prior to onset of the overt disease state. In the limited number of studies discussed below which investigate the relationship between biomarkers of vitamin D status and prostate cancer, we discuss this issue of the timepoint of gathering the biomarker data prior to diagnosis of the disease.

Corder et al. (1993, 1995) had access to more than 250000 serum samples collected between 1964 and 1971 from members of a Medical Care Program in Northern California. The samples were stored at $-23^{\circ} \mathrm{C}$ or colder until 1980 and subsequently were stored at $-40^{\circ} \mathrm{C}$ until analysis. Sera from 90 black and 91 white men diagnosed with prostate cancer before 1988 and controls individually matched for age, race and day of serum storage were analysed for $25-\mathrm{OH}-\mathrm{D}_{3}$ and $1,25-(\mathrm{OH})_{2}-\mathrm{D}_{3}$ in blinded fashion. Almost $90 \%$ of cases were diagnosed at least 5 years after serum was obtained, only three cases were diagnosed within 2 years of baseline. Despite the prolonged period of frozen storage, measured values of $25-\mathrm{OH}-\mathrm{D}_{3}$ and $1,25-(\mathrm{OH})_{2}-\mathrm{D}_{3}$ were generally within or above normative limits for the laboratory used, i.e. $15-80 \mathrm{ng} / \mathrm{ml}$ for $25-\mathrm{OH}-$ $\mathrm{D}_{3}$ and $19-50 \mathrm{pg} / \mathrm{ml}$ for $1,25-(\mathrm{OH})_{2}-\mathrm{D}_{3}$. No significant difference was reported (Corder et al. 1993) between cases and controls for serum $25-\mathrm{OH}-\mathrm{D}_{3}$ levels. However, cases had significantly $(P=0.002)$ lower mean serum levels of $1,25-(\mathrm{OH})_{2}-\mathrm{D}_{3}$ than matched controls. The association of lower $1,25-(\mathrm{OH})_{2}-\mathrm{D}_{3}$ with prostate cancer was found in men above the median age of 57 at serum storage but not in younger men and was similar in black and white men.

In a subsequent paper (Corder et al. 1995) on the same study group, these investigators reported data on the relationship between VDBP level (measured by radioimmunoassay (RIA)) and VDBP genotype (identified by isoelectric focusing) and prostate cancer. Serum levels of VDBP were essentially similar throughout the year and were comparable in cases and control subjects. VDBP allelic frequencies were markedly different in black and white men but did not differ between cases and controls within each ethnic group. The authors also reported evidence of seasonal variation in serum levels of 1,25$(\mathrm{OH})_{2}-\mathrm{D}_{3}$ in cases but not control subjects and suggested that men at elevated risk of prostate cancer have, on average, lower summer levels of serum $1,25-(\mathrm{OH})_{2}-\mathrm{D}_{3}$ compared to controls.

In contrast to the above studies, Braun et al. (1995) reported data that did not support the hypothesis that vitamin $\mathrm{D}$ metabolite levels are associated with prostate cancer risk. Serum samples were obtained from 20305 individuals between August and November 1974 and stored at $-70^{\circ} \mathrm{C}$. Subsequently, 61 individuals were diagnosed with prostate cancer during the period 1980-92. The average period between the blood collection and the diagnosis of prostate cancer was 14 years, minimising effects of disease on biomarker levels. Each prostate cancer case was matched to two controls on age ( \pm 1 year), month of serum collection and race. Serum $25-\mathrm{OH}-\mathrm{D}_{3}$ levels were measured by RIA and a radioreceptor assay was used to measure serum 1,25-(OH $)_{2}-\mathrm{D}_{3}$ levels. Each case-serum and its two matched control-sera were analysed sequentially on the same day. No statistically significant difference in serum levels of vitamin D metabolites was reported between cases and controls. These workers used reference sera during the analysis of $25-\mathrm{OH}-\mathrm{D}_{3}$ and $1,25-(\mathrm{OH})_{2}-\mathrm{D}_{3}$ and reported coefficients of variation which were higher than those reported by Gann et al. (1996). These authors also noted that other studies did not use external, masked, quality-control reference samples to validate their analytical data. Corder et al. (1993, 1995) made no comment on this issue in relation to the biomarkers used in their study.

Further evidence that high circulating levels of vitamin D metabolites are not associated with reduced prostate cancer risk was provided by a nested case-control study reported by Gann et al. (1996). Plasma samples from 14916 subjects were collected in 1982-83. The study protocol noted that a cold pack was used to keep specimens cool following collection until receipt the following morning when they were aliquoted and stored at $-82^{\circ} \mathrm{C}$. Subsequently, 232 prostate cancer cases were identified and confirmed. For each case, two controls were selected and matched for smoking status and age within one year. Of the 464 chosen controls 50 had too little plasma for 
vitamin D analysis, leaving 414 control samples in the analysis. Rigorous transport and storage conditions for samples were employed prior to analysis of $25-\mathrm{OH}-\mathrm{D}_{3}$ by RIA, $1,25-(\mathrm{OH})_{2}-\mathrm{D}_{3}$ by a radioreceptor assay using calf thymus receptor and VDBP by radial immunodiffusion assay. Each case and its matched control samples were assayed in the same run to eliminate interference from interassay variability. Sets of unidentifiable, identical quality control samples of pooled plasma were also analysed. The mean intra-assay $\mathrm{CV}$ for the quality control samples was $8.1 \%, 7.9 \%$ and $8.7 \%$, respectively, for the three parameters assayed. Little evidence was found for reduced prostate cancer risk in men with higher levels of either $25-\mathrm{OH}-\mathrm{D}_{3}$ or $1,25-(\mathrm{OH})_{2}-\mathrm{D}_{3}$ whether measured as total or free circulating hormone. No difference in VDBP levels was noted between cases and controls. The ratio of $25-\mathrm{OH}-\mathrm{D}_{3}$ to $1,25-(\mathrm{OH})_{2}-\mathrm{D}_{3}$, which may be viewed as an index of the efficiency of conversion of $25-\mathrm{OH}-\mathrm{D}_{3}$ to active metabolite, was also unrelated to prostate cancer development. These authors stated that the reasons for the discrepancy between their findings and those of Corder et al. $(1993,1995)$ are not obvious but they noted, validly, that their study was larger, had a prospective design with 10 years of follow-up, careful collection, storage and analysis of plasma specimens, thorough ascertainment of morbidity events in the cohort and biomarkers of free and bound vitamin $\mathrm{D}$ metabolites. However, they noted that complete exploration of the hypothesis should include studies of vitamin $\mathrm{D}$ receptor which has been located in the prostate and is subject to variations in activity associated with genetic polymorphisms.

Genetic polymorphisms in the vitamin D receptor have the advantage as a biomarker that the parameter does not change over the lifetime of the individual and can be applied in a traditional case-control design. Indeed work has been published associating prostate cancer risk with such polymorphisms. Ingles et al. (1997) reported on 57 white prostate cancer cases and 169 controls who were genotyped for a newly discovered polymorphism in the $3^{\prime}$ untranslated region of the vitamin $\mathrm{D}$ receptor (VDR) gene. Odds ratios (OR) were estimated by using logistic regression. An OR of 4.61 (95\% CI =1.34-15.82) was reported for individuals carrying at least one long (A18 to A22) VDR poly-A allele versus two short (A14 to A17) poly-A alleles. Furthermore, the at-risk genotypes were more strongly associated with advanced disease than with localised disease. The authors noted that, if confirmed, this genetic risk factor (VDR alleles) is among the strongest biomarkers yet identified for prostate cancer.

Taylor et al. (1996) tested the hypothesis that VDR gene polymorphisms are associated with prostate cancer risk using a case-control study of 108 men undergoing radical prostatectomy and 170 male urology clinic controls with no history of cancer. The results suggest that men who are homozygous for the $\mathrm{t}$ allele (shown to correlate with higher serum levels of the active form of vitamin D) have one third the risk $(\mathrm{OR}=0.34,95 \%$ CI $0 \cdot 16-0 \cdot 76, P<0.01)$ of developing prostate cancer requiring prostatectomy compared to men who are heterozygous or homozygous for the T allele. However, in a follow-up (Ma et al. 1998) to their earlier report (Gann et al. 1996), no significant associations of VDR polymorphisms (BsmI and TaqI) with prostate cancer risk were noted in a cohort of 372 prostate cancer cases and 591 controls.

The precise relationship between vitamin D status and prostate cancer risk remains unclear. The serological biomarkers, namely $25-\mathrm{OH}-\mathrm{D}_{3}$ and $1,25-(\mathrm{OH})_{2}-\mathrm{D}_{3}$ as well as VDBP levels are all subject to some limitations and reflect slightly different aspects of vitamin D status. 1,25$(\mathrm{OH})_{2}-\mathrm{D}_{3}$ has been used to reflect physiological status but this biomarker suffers from a short half-life, 25-OH-D levels are considered to be the best biomarker of vitamin D status and are used to reflect bioavailability. However, it is also recognised that interindividual variation in vitamin D receptor is influenced by genetic polymorphisms and could be an important modulator of the effects of vitamin D. Given this knowledge a combination of markers, serological and genetic is probably most informative. Further epidemiological studies possibly complemented by animal models and in vitro studies will be required to clarify the relationship, if any, between vitamin $\mathrm{D}$ and risk of prostate cancer.

\subsection{Cooked meat intake, heterocyclic amines and colorectal cancer}

High red meat consumption has been associated with an increased risk of colorectal cancer (WCRF/AICR, 1997). Furthermore, the method of cooking appears important with an increased risk in individuals consuming the meat wellcooked (Gerhardsson de Verdier et al. 1991). Heterocyclic amines (HAs) are pyrolysis products formed when meat (beef, chicken and fish) is well-cooked with the level of formation dependent on the temperature and duration of cooking (Knize et al. 1994). HA are potent mutagens and are carcinogenic in animals, inducing primarily colon and mammary gland tumours in rats (IARC, 1994). Estimates of exposure to the two major HAs in the diet in the USA, namely 2-amino-1-methyl-6-phenylimidazo(4,5-b)pyridine (PhIP) and 2-amino-3,8-dimethylimidazo[4,5-f]-quinoxaline (MeIQx) are 16.6 and $2.6 \mathrm{ng} / \mathrm{kg} /$ day, respectively. It is therefore important to investigate whether HAs are implicated in the cancer risk associated with red meat consumption.

Assessing human exposure to HAs from dietary questionnaires is difficult both because the exposure does not result from a single dietary source and more importantly because the method of cooking has a major influence on the HA level. In addition, HAs are a class of compounds and measurement of each of these in large numbers of food samples in the context of an epidemiological study is impractical. As mentioned above, estimates of USA population exposures have been made using recorded levels of HAs in cooked foods and data on frequency of food consumption (Layton et al. 1995). This approach is likely to be less accurate at an individual level because of the above-stated variation in cooking methods. Refinement of questionnaires to address the type of methods used and the degree of cooking of the meat (e.g. by photographs) may improve exposure assessment for HA but the approach is still limited by reliance on the database for HA levels in different food commodities (Byrne et al. 1998). Therefore, 
a major challenge in order to investigate the role of HAs in human cancer is to measure exposure at the individual level. Biomarkers may have a contribution to make in this respect. The HAs exert their action through DNA damage and subsequent mutation following metabolic activation and as such represent a paradigm for other dietary genotoxic carcinogens.

Quantitatively the major HAs in the western diet are PhIP and MeIQx and studies in volunteers eating fried beef have shown that approx. $1 \%$ of the ingested PhIP and a similar percentage of MeIQx is excreted unchanged in the urine (Lynch et al. 1992; Sinha et al. 1995). Urinary excretion of the HA is well correlated with intakes at the individual level. A potential limitation with this measure is the rapid excretion of the compounds following ingestion (essentially complete for PhIP within $8 \mathrm{~h}$ ) meaning that the measure is likely to reflect consumption over the previous few hours (Lynch et al. 1992). Furthermore, it is possible that the percentage of unmetabolised HA excreted in the urine is not constant between individuals but is influenced by, for example, the level of expression of cytochrome $P 450$ s, e.g. cytochrome P450 1A2 (CYP 1A2), which activate HA. Evidence for this comes from controlled feeding studies in which the urinary excretion of unmetabolised MeIQx was lower in individuals with high CYP1A2 activity (Sinha et al. 1995). Nevertheless the measurement of the parent HA does provide information on individual exposure and presents a useful addition to dietary questionnaires and food analysis. Certainly this type of urinary marker could be used in validating dietary questionnaire assessments of exposure and in examining the modulation of HA metabolism following consumption of different diets. Further refinement of urinary assays to include both HA and their metabolites in the urine will improve this approach.

PhIP and other HAs are converted into their reactive metabolites, $N$-acetoxy arylamines, via $N$-oxidation (CYP 1A2) and $O$-acetylation ( $N$-acetyltransferase-2 (NAT2)). These metabolites bind to DNA to form promutagenic DNA adducts. This understanding of the metabolism of HA in humans has permitted the study both of DNA adducts as markers of exposure and of individual susceptibility to HA-induced cancer resulting from polymorphisms in genes coding for enzymes implicated in HA metabolism.

Both CYP 1A2 and NAT2 expression exhibit interindividual variation due to environmental and genetic factors; expression of these enzymes can be characterised by examining urinary metabolites of the model substrate caffeine. It is hypothesised that individuals with rapid metaboliser genotypes for the enzymes are at higher risk of colorectal cancer following HA exposure. A study of 75 colorectal cancer/polyp patients and 205 controls was conducted (Lang et al. 1994) in which each individual was characterised for CYP 1A2 and NAT2 genotype by examining caffeine metabolism. In accord with the hypothesis, individuals who were rapid metabolisers for both enzymes represented $35 \%$ of cases and only $16 \%$ of controls (OR 2.79; $P=0.002$ ). Of particular interest was the fact that individuals with a preference for well-done meat who had the rapid/rapid metaboliser genotype had an odds ratio of 6.45 compared to individuals with a preference for rare/medium meat and a slow/slow genotype. This study suggests that there is a greater risk from well-done meat in individuals with a specific genotype for HA metabolism and is consistent with a role for HAs in the aetiology of colorectal cancer. Unfortunately to date there are no studies showing an effect of the genotype on the level of DNA adducts or mutations induced by a given intake of HA. However, the work of Sinha et al. (1995) showing a reduced level of unmetabolised MeIQx in the urine of individuals with rapid CYP1A2 metaboliser genotype is consistent with an increased metabolism of the parent compound to DNA reactive metabolites.

An alternative to measuring the carcinogens or their metabolites in body fluids is to measure the binding of HA to DNA as a marker of biologically effective dose. The measurements of DNA adducts provide an integration of exposure, absorption, metabolism and DNA repair and promise to provide an objective and relevant measure of exposure (Wild \& Pisani, 1997). The relevance results from the fact that the adduct is believed to be an important step in the disease pathway resulting in mutations in key cell growth and cell cycle control genes. The major DNA adduct of $\mathrm{PhIP}$ is the compound bound to the $\mathrm{C} 8$ position of deoxyguanosine. This adduct has been identified in human colon DNA by gas chromatography-mass spectrometry and ${ }^{32} \mathrm{P}$-post-labelling in two out of six colon cancer cases whereas twelve pancreas and six bladder specimens were negative (Friesen et al. 1994). In addition, MeIQx DNA adducts were detected in human kidney, rectum and colon samples by ${ }^{32} \mathrm{P}$-post-labelling and HPLC (Totsuka et al. 1996). These data demonstrate that HAs reach target cell DNA in humans but such approaches are limited in application because of their invasive nature. It is unclear to date whether adducts can be detected in more readily available sources of DNA, e.g. peripheral blood cells or buccal cells, and what the relationship would be with adduct levels in the colon. The stability of the adducts over time in the various tissues would also need to be investigated. None of these DNA adduct measurements have been utilised to date in epidemiological studies.

Mutation spectra have been suggested as an approach to identifying the aetiological agent in human tumours (Greenblatt et al. 1994). With respect to HA, Kakiuchi et al. (1995) demonstrated a characteristic frameshift mutation, namely deletion of a single guanine base in the sequence GGGA, in the rat apc gene in PhIP-induced colon tumours. This same mutation was induced by PhIP in the hprt gene of Chinese hamster V79 cells transfected with human CYP1A2 (Yadollahi-Farsani et al. 1996). Therefore, this single $G$ deletion in the sequence GGGA may be a mutational fingerprint for PhIP and indeed such mutations are observed in 5-10\% of sporadic human colorectal tumours (see Yadollahi-Farsani et al. 1996 for discussion). Again to date no epidemiological studies utilising this biomarker have been conducted.

Overall an understanding of the metabolism, DNA binding and mutagenicity of HA provide a basis for the development of both biomarkers of HA exposure and susceptibility to the carcinogenic action of these compounds. However, generally the studies conducted so far 
have focused on marker validation rather than integration into epidemiological studies investigating the aetiological role of HA in human cancer.

\section{Conclusions}

The above examples illustrate both the promise of biomarkers in the assessment of diet and health but also some of the limitations. Certainly biomarkers do have promise in providing a more accurate and objective measure of diet than estimates of current or usual intake. However, it also appears that the biomarker approach will not provide a solution to all the problems of the latter methodologies. A combination of methods will probably prove to be most valuable and this is the approach being taken in current large prospective studies. There are a number of key questions to bear in mind when assessing the use of biomarkers in studies of diet and health.

- It is important to understand the intraindividual variation in biomarkers and the possibility that a single measurement at a given point in time will not reflect the typical status of that individual.

- The timing of a measurement in relation to the natural history of the disease should be considered.

- Disease may affect the measured level of a biomarker and this is of concern particularly when measurements are made after diagnosis. In this respect prospective studies offer advantages.

- Biomarkers may correlate with intake but in some instances, e.g. metabolites or DNA adducts, the marker is an integration of intake, absorption, metabolism etc., and as such there may not be a straightforward correlation. However, these markers may be more informative with respect to risk of disease.

- Where there is homeostatic regulation of nutrient levels in body fluids there may be a poor correlation between biomarkers and intakes.

- Other factors including dietary or environmental constituents or the genetic background of the individual may modulate the correlation between dietary intake and biomarker.

- Poor quality control in collection, processing, storage and analysis of biological samples can compromise biomarker measurements.

\section{Acknowledgements}

The authors would like to thank Drs Janet Cade and Chris Schorah of the University of Leeds for their helpful comments on drafts of this document.

\section{References}

Adlercreutz H (1993) Dietary lignans and isoflavonoid phytoestrogens, and cancer. Clinical Laboratory 2a, 4-12.

Adlercreutz H (1995) Phytoestrogens: epidemiology and a possible role in cancer protection. Environmental Health Perspectives 103(Suppl 7); 103-112.

Adlercreutz H, Fotsis T, Bannwart C, Wäjälä K, Mäkelä T, Brunow G \& Hase T (1986) Determination of urinary lignans and phytoestrogen metabolites, potential antiestrogens and anticarcinogens, in urine of women on various habitural diets. Journal of Steroid Biochemistry 25, 791-797.
Adlercreutz H, Fotsis T, Heikkine R, Dwyer JT, Woods M, Goldin BR \& Gorbach SL (1982) Excretion of the lignans enterolactone and enterodiol and of equol in omnivorous and vegetarian postmenopausal women and in women with breast cancer. Lancet ii, 1295-1299.

Adlercreutz H, Fotsis T, Lampe J, Wähälä K, Mäkelä T, Brunow G \& Hase T (1993) Quantitative determination of lignans and isoflavonoids in plasma of omnivorous and vegetarian women by isotope dilution gas-chromatography mass-spectrometry. Scandinavian Journal of Clinical Laboratory Investigation 215, 5-18.

Adlercreutz CHT, Goldin BR, Gorbach SL, Höckerstedt KAV, Watanabe S, Hämäläinen EK, Markkanen MH, Mäkelä TH, Wähälä KT, Hase TA \& Fotsis T (1995) Soybean phytoestrogen intake and cancer risk. Journal of Nutrition 125, 757S-770S.

Adlercreutz H, Hanjo H, Higashi A, Fotsis T, Hämäläinen E, Hasegawa T \& Okada H (1991) Urinary excretion of lignans and isoflavonoid phytoestrogens in Japanese men and women consuming traditional Japanese diet. American Journal of Clinical Nutrition 54, 1093-1100.

Bailey LB \& Gregory JF (1999a) Folate metabolism and requirements. Journal of Nutrition 129, 779-782.

Bailey LB \& Gregory JF III (1999b) Polymorphisms of methylenetetrahydrofolate reductase and other enzymes, metabolic significance, risks and impact on folate requirement. Journal of Nutrition 129, 919-922.

Baird DD, Umbach DM, Lansdell L, Hughes CL, Setchell KDR, Weinberg CR, Haney AF, Wilcox AJ \& McLachlan JA (1995) Dietary intervention study to assess estrogenicity of dietary soy among postmenopausal women. Journal of Clinical and Endocrine Metabolism 80, 1685-1690.

Barnes S (1999) Phytoestrogens and breast cancer. Baillière's Clinical Endocrinology and Metabolism 12, 559-579.

Basu TK \& Dickerson JW (1996) Vitamins in Human Health and Disease. Wallingford: CAB International.

Beecher GR \& Khachik F (1992) Qualitative relationship of dietary and plasma carotenoids in human beings. Annals of the New York Academy of Sciences 669, 320-321.

Bennett MJ, Tershakovec AM, Cortner JA \& Shannon BM (1993) A quality assurance program for the measurement of capillary blood cholesterol levels in private paediatric practices The Children's Health Project. American Journal of Diseases in Children 147(3), 340-345.

Bourdoux PP (1993) Biochemical evaluation of iodine status. In Iodine Deficiency in Europe. A Continuing Concern, pp. 119-125 [F Delange, JT Dunn and D Glinoer, editors]. New York: Plenum Press.

Braun MM, Helzlsouer KJ, Hollis BW \& Comstock GW (1995) Prostate cancer and prediagnostic levels of serum vitamin D metabolites (Maryland, United States). Cancer Causes and Control 6, 235-239.

Brouwer IA, van Dusseldorp M, Thomas CMG, Duran M, Hautvast JGAJ, Eskes TKAB \& Steefers-Theunissen RPM (1999a) Low-dose folic acid supplementation decreases plasma homocysteine concentrations, a randomized trial. American Journal of Clinical Nutrition 69, 99-104.

Brouwer IA, van Dusseldorp $M$, West CE, Meyboom S, Thomas CMG, Duran M, van het Hof K, Eskes TKAB, Hautvast JGAJ \& Steefers-Theunissen RPM (1999b) Dietary folate from vegetables and citrus fruit decreases plasma homocysteine concentrations in humans in a dietary controlled trial. Journal of Nutrition 129, 1135-1139.

Brug J, Lowik MR, Wedel M \& Odink J (1992) Iodide excretion before and after revision of goiter prophylaxis (Dutch nutrition surveillance system). European Journal of Clinical Nutrition 46, 671-678.

Byrne C, Sinha R, Platz EA, Giovannucci E, Colditz GA, 
Hunter DJ, Speizer FE \& Willett WC (1998) Predictors of dietary heterocyclic amine intake in three prospective cohorts. Cancer, Epidemiology Biomarkers and Prevention 7, 523-530.

Cassidy A, Bingham S \& Setchell KDR (1994) Biological effects of a diet of soy protein rich in isoflavones on the menstrual cycle of premenopausal women. American Journal of Clinical Nutrition 60, 333-340.

Chen Z, Zheng W, Custer LJ, Dai Q, Shu X-O, Jin F \& Franke AA (1999) Usual dietary consumption of soy foods and its correlation with the excretion rate of isoflavonoids in overnight urine samples among Chinese women in Shanghai. Nutrition and Cancer 33, 82-87.

Clugston GA \& Hetzel BS (1994) Iodine. In Modern Nutrition in Health and Disease, 8th edn 1, pp. 252-263 [ME Shils, JA Olson and M Shike, editors]. Malver, PA: Lea and Febiger.

Cocker J, Nutley BP \& Wilson HK (1996) Methylene bis (2chloroaniline) (MbOCA), towards a biological monitoring guidance value. Biomarkers 1, 185-189.

Corder EH, Friedman GD, Vogelman JH \& Orentreich N (1995) Seasonal variation in vitamin $\mathrm{D}$, vitamin $\mathrm{D}$-binding protein and dehydroepiandrosterone. Risk of prostate cancer in black and white men. Cancer, Epidemiology Biomarkers and Prevention 4, 655-659.

Corder EH, Guess HA, Hulka BS, Friedman GD, Sadler M, Vollmer RT, Lobaugh B, Drezner MK, Vogelman JH \& Orentreich N (1993) Vitamin D and prostate cancer, a prediagnostic study with stored sera. Cancer, Epidemiology Biomarkers and Prevention 2, 467-472.

Cunnane SC, Hamadeh MJ, Liede AC, Thompson LU, Wolever TMS \& Jenkins DJA (1995) Nutritional attributes of traditional flaxseed in healthy young adults. American Journal of Clinical Nutrition 61, 62-68.

Czeizel AE (1995) Folic acid in the prevention of neural tube defects. Journal of Pediatric Gastroenterology and Nutrition 2 , 4-16.

de Bree A, van Dusseldorp M, Brouwer IA, van het Hof KH \& Steegers-Theunissen RPM (1997) Folate intake in Europe, recommended, actual and desired intake. European Journal of Clinical Nutrition 51, 643-660.

De Plaen P, Claeys-Thoreau F \& De Boeck R (1996) External quality assessment scheme in Belgium. Heavy metal analyses. Annals of the Institute Super Sanita 32(2), 215-220.

Duff EM \& Cooper ES (1994) Neural tube defects in Jamaica following Hurricane Gilbert. American Journal of Public Health 84, 473-476.

Dunn JT (1993) Techniques for measuring urinary iodine an update http://www.mn-net.org/index.cfm?fuseaction=show Article\&article_id=72.Date:010601.10p.

Evans RW, Sankey SS, Hauth BA, Sutton-Tyrrell K, Kamboh MI \& Kuller LH (1996) Effect of sample storage on quantitation of lipoprotein(a) by an enzyme-linked immunosorbent assay. Lipids 31(11), 1197-1203.

Fleming A \& Copp AJ (1998) Embryonic folate metabolism and mouse neural tube defects. Science 280, 2107-2109.

Franke AA \& Custer LJ (1994) High-performance liquid chromatographic assay of isoflavonoids and coumestrol from human urine. Journal of Chromatography B 662, 47-60.

Frerichs RR, Silarug N, Eskes N, Pagcharoenpol P, Rodklai A, Thangsupachai S \& Wongba C (1994) Saliva-based HIVantibody testing in Thailand. AIDS 8(7), 885-894.

Friesen MD, Kaderlik K, Lin D, Garren L, Bartsch H, Lang NP \& Kadlubar FF (1994) Analysis of DNA adducts of 2-amino-1methyl-6-phenylimidazo[4,5-b]pyridine in rat and human tissues by alkaline hydrolysis and gas chromatography/electron capture mass spectroscopy, validation by comparison with ${ }^{32} \mathrm{P}$ postlabelling. Chemical Research in Toxicology 7(6), 733-739. Ganguly S, Taioli E, Baranski B, Cohen B, Toniolo P \& Garte SJ
(1996) Human metallothionein gene expression determined by quantitative reverse transcription-polymerase chain reaction as a biomarker of cadmium exposure. Cancer Epidemiology Biomarkers and Prevention 5(4), 297-301.

Gann PH, Ma J, Hennekens CH, Hollis BW, Haddad JG \& Stampfer MJ (1996) Circulating vitamin D metabolites in relation to subsequent development of prostate cancer. Cancer Epidemiology Biomarkers and Prevention 5, 121-126.

Gerhardsson de Verdier M, Hagman U, Peters RK, Steineck G \& Overvik E (1991) Meat, cooking methods and colorectal cancer, a case referent study in Stockholm. International Journal of Cancer 49, 1-6.

Gibson RS (1990) Principles of Nutritional Assessment. New York: Oxford University Press.

Gompertz D (1997) Quality control of biomarker measurements in epidemiology. IARC Scientific Publications 142, 215-222.

Greenblatt MS, Bennett WP, Hollstein M \& Harris CC (1994) Mutations in the p53 tumor suppressor gene, clues to cancer etiology and molecular pathogenesis [review]. Cancer Research 54, 4855-4878.

Gunter EW, Bowman BA, Caudill SP, Twite DB, Adam MJ \& Sampson EJ (1996) Results of an international round robin for serum and whole-blood folate. Clinical Chemistry 42, 16891694.

Hanchette CL \& Schwartz GG (1992) Geographic patterns of prostate cancer mortality. Evidence for a protective effect of ultraviolet radiation. Cancer 70, 2861-2869.

Herbert VD \& Colman N (1988) Folic acid and vitamin $B_{12}$. In Modern Nutrition in Health and Disease, Chap 21, pp. 388-413 [ME Shils and VR Young, editors] Philadelphia, PA: Lea \& Febiger.

Herman C, Adlercreutz H, Goldin BR, Gorbach SL, Höckerstedt KAV, Watanabe S, Hämäläinen EK, Markkanen MH, Mäkelä TH, Wäjälä KT, Hase TA \& Fotsis T (1995) Soybean phytoestrogen intake and cancer risk. Journal of Nutrition 125, 757S-770S.

Hetzel BS \& Dunn JT (1989) The iodine deficiency disorders, their nature and prevention. Annual Reviews of Nutrition 9, 21-38.

Holick MF (1990) The use and interpretation of assays for vitamin D and its metabolites. Journal of Nutrition 120, 1464-1469.

Horn-Ross PL, Barnes S, Kirk M, Coward L, Parsonnet J \& Hiatt RA (1997) Urinary phytoestrogen levels in young women from a multiethnic population. Cancer Epidemiology Biomarkers and Prevention 6, 339-345.

Humfrey CDN (1998) Phytoestrogens and human health effects, weighing up the current evidence. Natural Toxins 6, 51-60.

Hurrell RF (1997) Bioavailability of iodine. European Journal of Clinical Nutrition 51(Suppl 1), S9-S12.

Hussain SP \& Harris CC (1998) Molecular epidemiology of human cancer, contribution of mutation spectra studies of tumour suppressor genes. Cancer Research 58, 4023-4037.

Hutchins, AM, Slavin JL \& Lampe JW (1995) Urinary isoflavonoid phytoestrogen and lignan excretion after consumption of fermented and unfermented soy products. Journal of the American Dietetic Association 95, 545-551.

IARC (1992) Cancer Incidence in Five Continents. IARC Scientific Publications no 120, Lyon: IARC.

IARC (1994) IARC Scientific Publication no 56, Lyon: IARC.

Ingles SA, Ross RK, Yu MC, Irvine RA, La Pera G, Haile RW \& Coetzee GA (1997) Association of prostate cancer risk with genetic polymorphisms in vitamin $\mathrm{D}$ receptor and androgen receptor. Journal National Cancer Institute 89, 166-170.

Ingram D (1998) Phyto-oestrogens and breast cancer. Authors reply. Lancet 351, 138-139.

Jacob RA, Wu M-M, Henning SM \& Swendseid ME (1994) Homocysteine increases as folate decreases in plasma of 
healthy men during short-term dietary folate and methyl group restriction Journal of Nutrition 124, 1072-1080.

Kaaks R, Riboli E \& Sinha R (1997) Biochemical markers of dietary intake. IARC Scientific Publications 142, pp. 103-126. Lyon: IARC.

Kakiuchi H, Watanabe M, Ushijima T, Toyota M, Imai K, Weisburger JH, Sugimura T \& Nagao M (1995) Specific 5'GGGA-3' $\rightarrow 5^{\prime}$-GGA-3' mutation of the Apc gene in rat colon tumors induced by 2-amino-1-methyl-6-phenylimidazo[4,5-b]pyridine. Proceedings of the National Academy of Sciences USA 92, 910-914.

Karr SC, Lampe JW, Hutchins AM \& Slavin JL (1997) Urinary isoflavonoid excretion in humans is dose dependent at low to moderate levels of soy-protein consumption. American Journal of Clinical Nutrition 66, 46-51.

Key T, Oakes S, Davey G, Moore J, Edmond LM, McLoone UJ \& Thurnham DI (1996) Stability of vitamins A, C and E, carotenoids, lipids and testosterone in whole blood stored at $4^{\circ} \mathrm{C}$ and 24 hours before separation of serum and plasma. Cancer Epidemiology Biomarkers and Prevention 5(10), 811814.

King RA \& Bursill DB (1998) Plasma and urinary kinetics of the isoflavones daidzein and genistein after a single soy meal in humans. American Journal of Clinical Nutrition 67, 867-872.

Kirke PN, Mollowy AM, Daly LE, Burke H, Weir DG \& Scott JM (1993) Maternal plasma folate and vitamin B12 are independent risk factors for neural tube defects. Quarterly Journal of Medicine 86, 703-708.

Kirkman LNM, Lampe JW, Campbell DR, Martini MC \& Slavin JL (1995) Urinary lignan and isoflavonoid excretion in men and women consuming vegetable and soy diets. Nutrition and Cancer 24, 1-12.

Knize MG, Dolbeare FA, Carroll KL \& Felton JS (1994) Effects of cooking time and temperature on the heterocyclic amine content of fried-beef patties. Food Chemistry and Toxicology 32, 595-603.

Kohlmeier L (1995) Future of dietary exposure assessment. American Journal of Clinical Nutrition 61(suppl), 702S-709S.

Kohlmeier L, Kark J, Gomez-Gracia E, Martin B, Steck S, Kardinaal A, Ringstead J, Thamm M, Masaeu V, Riemersma R, Martin-Moreno J, Huttunen J \& Kok F (1997) Lycopene and myocardial infarction risk in the EURAMIC study. American Journal of Epidemiology 146(8), 618-626.

Kopp P (1998) Resveratrol, a phytoestrogen found in red wine. A possible explanation for the conundrum of the French paradox? European Journal of Endocrinology 138, 619-620.

Krumdieck CL, Fukushima K, Fukushima T, Shiota $\mathrm{T} \&$ Butterworth CE Jr (1978) A long-term study of the excretion of folate and pterins in a human subject after ingestion of ${ }^{14} \mathrm{C}$ folic acid, with observations on the effect of diphenylhydantoin administration. American Journal of Clinical Nutrition 31, 8893.

Kuiper GGJM, Enmark E, Peltohuikki MN, Bilsson S \& Gustafsson JA (1996) Cloning a novel estrogen receptor expressed in rat prostate and ovary. Proceedings of the National Academy of Sciences USA 93, 5925-5930.

Lamberg BA (1993) Review. Iodine deficiency disorders and endomic goitre. European Journal of Clinical Nutrition 47, $1-8$.

Lampe JW, Martini MC, Kurze MS, Adlercreutz H \& Slavin JL (1994) Urinary lignan and isoflavonoid excretion in premenopausal women consuming flaxseed powder. American Journal of Clinical Nutrition 60, 122-128.

Landi MT \& Caporaso N (1997) Sample collection, processing and storage. IARC Scientific Publication no. 142, pp. 223-236. Lyon: IARC.

Lang NP, Butler MA, Massengill J, Lawson M, Stotts RC,
Hauer Jense M \& Kadlubar FF (1994) Rapid metabolic phenotypes for acetyltransferase and cytochrome P4501A2 and putative exposure to food-borne heterocyclic amines increase the risk for colorectal cancer or polyps. Cancer Epidemiology Biomarkers and Prevention 3, 675-682.

Larsen WJ (1993) Human Embryology. New York, Churchill Livingstone p. 479.

Layton DW, Bogen KT, Knize MG, Hatch FT, Johnson VM \& Felton JS (1995) Cancer risk of heterocyclic amines in cooked foods, an analysis and implications for research. Carcinogenesis 16, 39-52.

Locksmith GJ \& Duff P (1998) Preventing neural tube defects, the importance of periconceptional folic acid supplements. Obstetrics and Gynecology 91, 1027-1034.

Lu L-JW \& Anderson KE (1998) Sex and long-term soy diets affect the metabolism and excretion of soy isoflavones in humans. American Journal of Clinical Nutrition 68, 1500S1504 S.

Lu L-JW, Grady JJ, Marshall MV, Ramanujam VMS \& Anderson KE (1995) Altered time course of urinary daidzein and genistein excretion during chronic soya diet in healthy male subjects. Nutrition and Cancer 24, 311-323.

Lu L-JW, Lin S-N, Grady JJ, Marshall MV, Nagamani M \& Anderson KE (1996) Altered kinetics and extent of urinary daidzein and genistein excretion in women during chronic soya exposure. Nutrition and Cancer 26, 289-302.

Lynch AM, Knize MG, Bobbis AR, Gooderham NJ, Davies DS \& Murray S (1992) Intra- and interindividual variability in systemic exposure in humans to 2-amino-3,8-dimethylimidazo[4,5-f]quinoxaline and 2-amino-1-methyl-6-phenylimidazo[4,5-b]pyridine, carcinogens present in cooked beef. Cancer Research 52, 6216-6223.

Ma J, Stampfer MJ, Gann PH, Hough HL, Giovannucci E, Kelsey KT, Hennekins CH \& Hunter DJ (1998) Vitamin D receptor polymorphisms, circulating vitamin D metabolites and risk of prostate cancer in United States physicians. Cancer Epidemiology Biomarkers and Prevention 7, 385-390.

Mäkelä S, Strauss L, Saarinen N, Ahotupa M \& Santti R (1998) Biological effects of phytoestrogens. In COST 916 Workshop 'Phyto-oestrogens, Exposure, Bioavailability, Health Benefits and Safety Concerns', pp. 26-27, Doorwerth, The Netherlands.

Mazur W (1999) Phytoestrogen content in foods. Baillière's Clinical Endocrine Metabolism 12, 729-742.

Michaud DS, Giovannucci EL, Ascherio A, Rimm EB, Forman MR, Sampson L \& Willett WC (1998) Associations of plasma carotenoid concentrations and dietary intake of specific carotenoids in samples of two prospective cohort studies using a new carotenoid database. Cancer Epidemiology Biomarkers and Prevention 7, 283-290.

Mills JL, McPartlin JM, Kirke PN, Lee YJ, Conley MR \& Weir DG (1995) Homocysteine metabolism in pregnancies complicated by neural-tube defects. Lancet 345, 149-151.

Mills JL, Scott JM, Kirke PN, McPartlin JM, Conley MR, Weir DG, Molloy AM \& Lee YJ (1996) Homocysteine and neural tube defects. Journal of Nutrition 126, 756S-760S.

Mitchell JH \& Collins AR (1998) Effects of a soya milk supplement on oxidative DNA damage in men a pilot study. In COST 916 Workshop 'Phyto-oestrogens, Exposure, Bioavailability, Health Benefits and Safety Concerns' p. 28, Doorwerth, The Netherlands.

Møller A (1996) Levnedsmiddeltabeller, 4th edn, pp. 1717. Levnedsmiddelstyrelsen, Søborg.

Morton M, Matos-Ferreira A \& Abranches-Monteiro L et al. (1997) Measurement and metabolism of isoflavonoids and lignans in the human male. Cancer Letters 114, 145-151.

MRC Vitamin Study Research Group (1991) Prevention of neural 
tube defects. Results of the Medical Research Council vitamin study. Lancet 338, 131-137.

Nesbitt P, Lam Y \& Thompson L (1999) Human metabolism of mammalian lignan precursors in raw and processed flaxseed. American Journal of Clinical Nutrition 69, 549-555.

O'Keefe CA, Bailey LB, Thomas EA, Hofler, SA, Davis BA, Cerda JJ \& Gregory JF (1995) Controlled dietary folate affects folate status in nonpregnant women. Journal of Nutrition 125, 2717-2725.

Parker SL, Tong T, Bolden S \& Wingo PA (1996) Cancer statistics 1996. CA Cancer Journal for Clinicians 46, 5-26.

Perera FP (1996) Molecular epidemiology, insights into cancer susceptibility, risk assessment and prevention (review). Journal of the National Cancer Institute 88, 496-509.

Pero R, Olsson A, Berglund G, Janzon L, Larsson SA \& Elmstahl S (1993) The Malmo biological bank. Journal of International Medicine 233, 63-67.

Pero RW, Olsson A, Bryngelsson C, von Schantz T, Carlsson S, Janzon L, Berglund G \& Elmstahl S (1998a) Quality control program for storage of biologically banked blood specimens in the Malmo diet and cancer study. Cancer Epidemiology Biomarkers and Prevention 7, 803-808.

Pero RW, Olsson A, Bryngelsson C, von Schantz T, Simanaitis M, Sternb NH, Larsson SA, Elmstahl S, Janzon L \& Berglund G (1998b) Feasibility and quality of biological banking of human normal and tumour tissue specimens as sources of DNA for the malmo diet and cancer study. Cancer Epidemiology Biomarkers and Prevention 7, 809-812.

Price KR \& Fenwick GR (1985) Naturally occurring oestrogens in foods - a review. Food Additives and Contaminants 2, 73-106.

Rasmussen LB, Ovesen L \& Christiansen E (1999) Day-to-day and within-day variation in urinary excretion. European Journal of Clinical Nutrition 53, 401-407.

Reinli K \& Block G (1996) Phytoestrogen content of foods - a compendium of literature values. Nutrition and Cancer 26, $123-148$.

Riboli E (1992) Nutrition and cancer, background and rationale of the European Prospective Investigation into Cancer and Nutrition (EPIC). Annals of Oncology 3, 783-791.

Riboli E, Slimani N \& Kaaks R (1996) Identifiability of food components for cancer chemoprevention. In Principles of Chemoprevention, pp. 23-31 [BW Stewart, D McGregor and P Kleihues, editors]. IARC Scientific Publications, no. 139, Lyon: IARC.

Rush D (1994) Periconceptional folate and neural tube defects. American Journal of Clinical Nutrition 59(suppl), 511S-516S.

Seow A, Shi CY, Franke AA, Hankin JH, Lee HP and Yu MC (1998) Isoflavonoid levels in spot urine are associated with frequency of dietary soy intake in a population-based sample of middle-aged and older Chinese in Singapore. Cancer Epidemiology Biomarkers and Prevention 7, 135-140.

Setchell KDR (1998) Phytoestrogens, the biochemistry, physiology, and implications for human health of soy isoflavones. American Journal of Clinical Nutrition 68, 1333S-1346S.

Shane B (1995) Folate chemistry and metabolism. In Folate in Health and Disease, pp. 1-22 [LB Bailey, editor]. New York: Marcel Dekker.

Sinha R, Rothman N, Mark SD, Murray S, Brown ED, Levander OA, Davies DS, Lang NP, Kadlubar FF \& Hoover RN (1995) Lower levels of urinary 2-amino-3,8dimethylimidazo[4,5-f]-quinoxaline (MeIQx) in humans with higher CYP1A2 activity. Carcinogenesis 16, 2859-2861.

Slattery ML \& Janerich DT (1991) The epidemiology of neural tube defects. A review of dietary intake and related factors as etiologic agents. American Journal of Epidemiology 133, 526540.

Slavin JL, Karr SC, Hutchins AM \& Lampe JW (1998) Influence of soybean processing, habitual diet, and soy dose on urinary isoflavonoid excretion. American Journal of Clinical Nutrition 68(suppl), 1492S-1495S.

Smithells RW, Nevin NC, Seller MJ, Sheppard S, Harris R, Read AP, Fielding DW, Walker S, Schorah CJ \& Wild CJ (1983) Further experience of vitamin supplementation for prevention of neural tube defect recurrences. Lancet i, 10271031.

Smithells RW, Sheppard S \& Schorah CJ (1976) Vitamin deficiencies and neural tube defects. Archives of Disease in Childhood 51(12), 944-950.

Smithells RW, Sheppard S, Schorah CJ, Seller MJ, Nevin NC, Harris R, Read AP \& Fielding DW (1980) Possible prevention of neural-tube defects by periconceptional vitamin supplementation. Lancet i, 339-340.

Stahl W \& Sies H (1992) Uptake of lycopene and its geometrical isomers is greater from heat-processed than from unprocessed tomato juice in humans. Journal of Nutrition 122, 2161-2166.

Stansbury JB (1988) Iodine. In Modern Nutrition in Health and Disease, pp. 227-237 [ME Shils and VR Young, editors]. Philadelphia: Lea and Febiger.

Stellman SD, Djordjevic MV, Muscat JE, Gong L, Bernstein D, Citron ML, White A, Kemeny M, Busch E \& Nafziger AN (1998) Relative abundance of organochlorine pesticides and polychlorinated biphenyls in adipose tissue and serum of women in Long Island, New York. Cancer Epidemiology Biomarkers and Prevention 7, 489-496.

Stites TE, Bailey LB, Scott KC, Toth JP, Fisher WP \& Gregory JF (1997) Kinetic modeling of folate metabolism through use of chronic administration of deuterium-labeled folic acid in men. American Journal of Clinical Nutrition 65, 53-60.

$\mathrm{Su}$ L-CJ, Bui M, Kardinaal A, Gomez-Aracena J, MartinMoreno J, Martin B, Thamm M, Simonsen N, van't Veer P, Kok F, Strain S \& Kohlmeier L (1998) Differences between plasma and adipose tissue biomarkers of carotenoids and tocopherols. Cancer Epidemiology Biomarkers and Prevention 7, 1043-1048.

Taylor JA, Hirvonen A, Watson M, Pittman G, Mohler JL \& Bell DA (1996) Association of prostate cancer with vitamin D receptor gene polymorphism. Cancer Research 56, 4108-4110.

Tham DM, Garder CD \& Haskell WL (1998) Potential health benefits of dietary phytoestrogens. A review of the clinical, epidemiological, and mechanistic evidence. Journal of Clinical and Endocrine Metabolism 83, 2223-2235.

Thomson CD, Colls AJ, Conaglen JV, Macormack M, Stiles M \& Mann J (1997) Iodine status of New Zealand residents as assessed by urinary iodine excretion and thyroid hormones. British Journal of Nutrition 78, 901-912.

Thomson CD, Smith TE, Butler KA \& Packer MA (1996) An evaluation of urinary measures of iodine and selenium status. Journal of Trace Elements in Medicine and Biology 10, 214222.

Totsuka Y, Fukutome K, Takahashi M, Takahashi S, Tada A, Sugimura T \& Wakabayashi K (1996) Presence of N2-(dG-C8MelQx) in human tissues. Carcinogenesis 17, 1029-1034.

Ward M, McNulty H, McPartlin J, Strain JJ, Weir DG \& Scott JM (1997) Plasma homocysteine, a risk factor for cardiovascular disease, is lowered by physiological doses of folic acid. Quarterly Journal of Medicine 90, 519-524.

Watanabe S, Yamaguchi M, Sobue T, Takahashi T, Miura T, Arai Y, Mazur W, Wäjälä K \& Adlercreutz H (1998) Pharmacokinetics of soybean isoflavones in plasma, urine and feces of men after ingestion of $60 \mathrm{~g}$ braked soybean powder (Kinako). Journal of Nutrition 128, 1710-1715.

WCRF/AICR (World Cancer Research Fund and American Institute for Cancer Research) (1997) Food, Nutrition and the 
Prevention of Cancer, a Global Perspective. Washington, DC: American Institute for Cancer Research.

Werler MM, Shapiro S \& Mitchell AA (1993) Periconceptional folic acid exposure and risk of occurrent neural tube defects. Journal of the American Medical Association 269, 1257-1261.

Westgard JO, Peterson PH \& Wiebe DA (1991) Laboratory process specifications for assuring quality in the US National Cholesterol Education Program. Clinical Chemistry 37(5), 656-661.

Wild CP \& Pisani P (1997) Carcinogen-DNA and carcinogenprotein adducts in molecular epidemiology, IARC Scientific Publication No. 142. In Applications of Biomarkers in Cancer Epidemiology, pp. 143-158 [P Toniola, P Boffetta, DEG Shuker, N Rothman, B Hulka and N Pearce, editors]. Lyon, France: International Agency for Research on Cancer.

Wild CP, Hudson GJ, Sabbioni G, Chapot B, Hall AJ, Wogan GN, Whittle H, Montesano R \& Groopman JD (1992) Dietary intake of aflatoxins and the level of albumin bound aflatoxin in peripheral blood in The Gambia, West Africa. Cancer Epidemiology Biomarkers and Prevention 1, 229-234.

Xu X, Harris KS, Wang H-J, Murphy PA \& Hendrich S (1995)
Bioavailability of soybean isoflavones depends upon gut microflora in women. Journal of Nutrition 125, 2307-2315.

Xu X, Wang H-J, Murphy PA, Cook L \& Hendrich S (1994) Daidzein is a more bioavailable soymilk isoflavone than is genistein in adult women. Journal of Nutrition 124, 825-832.

Yadollahi-Farsani M, Gooderham NJ, Davies DS \& Boobis AR (1996) Mutational spectra of the dietary carcinogen 2-amino-1methyl-6-phenylimidazo[4,5-b]pyridine(phip) at the Chinese hamsters hprt locus. Carcinogenesis 17, 617-624.

Yu MC, Ho JHC, Lai SH \& Henderson BE (1986) Cantonese style salted fish as a cause of nasopharyngeal carcinoma, report of a case-control study in Hong Kong. Cancer Research 46, 956-961.

Zeleniuch-Jacquotte A, Adlercreutz $\mathrm{H}$, Akhmedkhanov A \& Toniolo P (1998) Reliability of serum measurements of lignans and isoflavonoid phytoestrogens over a two-year period. Cancer Epidemiology Biomarkers and Prevention 7, 885-889.

Zhang Y, Wang G-J, Song TT, Murphy PA \& Hendrich S (1999) Urinary disposition of soybean isoflavones daidzein, genistein and glycitein differs among humans with moderate fecal isoflavone degradation activity. Journal of Nutrition 129, 957-962. 